\title{
Synergistic Antioncogenic Activity of Azacitidine and Curcumin in Myeloid Leukemia Cell Lines and Patient Samples
}

\author{
IVÁN MARTÍN ${ }^{1}$, BLANCA NAVARRO ${ }^{1,2}$, CARLOS SOLANO $^{1,3}$, MARISA CALABUIG $^{1}$, \\ JUAN CARLOS HERNÁNDEZ-BOLUDA ${ }^{1}$, PAULA AMAT ${ }^{1}$, MARÍA JOSÉ REMIGIA ${ }^{1}$, \\ FRANCISCA GARCÍA $^{1}$, EVA VILLAMÓN $^{1 *}$ and MAR TORMO ${ }^{1 *}$ \\ ${ }^{1}$ Hematology Department, Hospital Clínico Universitario, \\ INCLIVA Research Institute, University of Valencia, Valencia, Spain; \\ ${ }^{2}$ Department of Physiology, School of Medicine, University of Valencia, Valencia, Spain; \\ ${ }^{3}$ Department of Medicine, School of Medicine, University of Valencia, Valencia, Spain
}

\begin{abstract}
Background/Aim: Azacitidine (AZA) is a hypomethylating agent used in myeloid neoplasms, however, approximately half of patients show treatment failure or relapse. This in vitro study investigated the effect of the combination of AZA with the natural compound curcumin (CUR) in increasing its efficacy. Materials and Methods: We analyzed the effects of AZA plus CUR on proliferation, apoptosis, cell cycle and differentiation in myeloid leukemic cell lines (U-937, HL-60, K562, and OCI-AML3) and bone marrow samples of patients. Results: The results showed a synergy between AZA and CUR in all leukemic lines and in most leukemic samples, with a decrease in proliferation and an increase in apoptosis compared to the activity of each drug separately. In addition, AZA plus CUR showed low cytotoxicity in healthy samples. Conclusion: A remarkable antioncogenic effect of the combination of AZA plus CUR was shown, providing a basis for future studies analyzing the clinical efficacy of these drugs.
\end{abstract}

Myelodysplastic syndromes (MDS) and acute myeloid leukemia (AML) are two heterogeneous groups of hematopoietic myeloid neoplasms. Although the neoplastic process is more aggressive in AML, common phenomena of epigenetic dysregulation and mutations have been identified. Despite major advances in biological understanding of both diseases, basic treatment principles have hardly varied.

\footnotetext{
*These Authors contributed equally to this work and should be considered as co-senior Authors.

Correspondence to: Mr. Iván Martín Castillo, Hematology Department, Hospital Clínico Universitario, Avenida Blasco Ibáñez, 17, 46010 Valencia, Spain. Tel: +34 961973842 e-mail: marcasi@alumni.uv.es

Key Words: Myelodysplastic syndromes, acute myeloid leukemia, azacitidine, curcumin, synergistic activity.
}

Aberrant methylation of tumor-suppressor gene promoters in myeloid diseases has been traced to their most immature cells, suggesting that this alteration is an important factor in their pathogenesis (1). Azacitidine (AZA) is a hypomethylating agent that inhibits DNA methyltransferase at sufficiently low doses to avoid cytotoxicity, and can reverse the transcriptional silence of tumor-suppressor genes. It has also been observed, in leukemic cell assays, that restoration of methylation by AZA inhibits growth, induces apoptosis, alters cell cycle and promotes differentiation (2-4). The use of AZA is currently approved by the Food and Drug Administration and European Medicines Agency for use in MDS and in older patients ( $\geq 65$ years) with newly diagnosed AML. Despite the promising initial results in both diseases (overall response rates of 30 to $50 \%$ ), approximately half of patients fail to respond to treatment or relapse (5-7). Moreover, recent findings have shown that AZA would only affect sub-clonal blasts, while founder clones would not be eliminated and would continue to drive clonal hematopoiesis (8).

In order to improve the response rate to hypomethylating agents such as AZA in the treatment of myeloid neoplasms, research is being conducted combining them with other molecules with different mechanisms of action such as histone modifiers (vorinostat), kinase inhibitors (midostaurin), Bcl-2 inhibitors (venetoclax) and antimetabolic agents (cytarabine) $(9,10)$.

Curcumin (CUR), a hydrophobic polyphenol derived from the plant Curcuma longa, inhibits histone deacetylases and induces apoptosis in both solid and hematologic tumors (1115). In leukemic cell assays, CUR affects growth, apoptosis, and cell cycle (16-17). In addition, in vitro studies have shown that CUR can induce glioma cell differentiation (18), although leukemic cell differentiation has only been observed when combined with other compounds (19). In vitro assays with dimethoxycurcumin (structural analog of CUR) have shown minimal cytotoxicity and enhanced 
antioncogenic activity in combination with decitabine, a hypomethylating agent (20). The combination of AZA and CUR has not yet been tested in hematological neoplasms, but in solid tumors a positive interaction between these drugs has been observed (21). Interestingly, CUR has also been tested in several clinical trials and proved to be safe, non-toxic and efficient as a single agent or combined with other therapies $(9,22,23)$. Finally, although the low water solubility of CUR hinders its initial bioavailability in the bloodstream, it has recently been reported that combining it with organometallic compounds enhances significantly its transport to cancer cells (24).

Based on these previous data, the aim of the current study was to investigate the combined effect of AZA plus CUR on proliferation, apoptosis, cell cycle and differentiation, of myeloid leukemia cell lines and bone marrow patient samples of AML and MDS.

\section{Materials and Methods}

Human acute leukemia cell lines, patient samples and culture medium. First, we examined four well-established human AML cell lines (HL-60, U-937, K-562, OCI-AML3) that are commonly used to study the biological properties and drug response of AML cells. Next, we also analyzed bone marrow cells from six patients with myeloid neoplasms and two healthy donors. Bone marrow samples were treated to lyse erythrocytes with BD Pharm Lyse buffer (BD Biosciences, San José, CA, USA) following the manufacturer's instructions. Leukemia cells were maintained in RPMI medium with $10 \%$ heat-inactivated fetal bovine serum (HL-60, U-937, K-562, and patient samples) or $\alpha$-MEM with $20 \%$ of heat-inactivated fetal bovine serum (OCI-AML3). Both media were supplemented with 100 units $/ \mathrm{ml}$ penicillin and $100 \mathrm{mg} / \mathrm{ml}$ streptomycin. Cells were grown at $37^{\circ} \mathrm{C}$ in a humidified atmosphere containing $5 \% \mathrm{CO}_{2}$. All cell lines used were obtained from Leibnitz Institute DSMZ German Collection of Microorganisms and Cell Cultures. All bone marrow samples of patients and healthy donors were acquired from the biobank of Hospital Clínico Universitario of Valencia with written informed consent in accordance with the Declaration of Helsinki and the approval of the internal review of Bioethics and Medical Research of the Hospital Clínico Universitario of Valencia.

Reagents. Curcumin (Sigma, St. Louis, MO, USA) was dissolved in DMSO as a stock solution at $50 \mathrm{mM}$. Azacitidine (Sigma) was dissolved in RPMI medium at $0.5 \mathrm{mM}$. Both reagents were aliquoted and stored in dark at $-20^{\circ} \mathrm{C}$.

Proliferation assay. In $100 \mu \mathrm{l}$ of medium, $10^{5}$ cells/well (cell lines) or 100000 cells/well (patient samples) were seeded in 96-well plates and were treated for 24 and $48 \mathrm{~h}$ with $\operatorname{AZA}(1,2$, and $4 \mu \mathrm{M})$, CUR $(5,10$, 20 , and $40 \mu \mathrm{M})$ and different combinations of AZA plus CUR. Cells were analyzed for proliferation by a colorimetric method determining the viable cell number using the CellTiter $96{ }^{\circledR}$ Aqueous One Solution Cell Proliferation Assay (Promega, Madison, WI, USA) following the manufacturer's instructions. The absorbance values were recorded at $450 \mathrm{~nm}$ after incubation at $37^{\circ} \mathrm{C}$ for $3 \mathrm{~h}$ and corrected by subtracting the background absorbance (culture media alone). All samples and controls were run in triplicate. Cell viability percentages were calculated as follows: cell viability $\%=[$ absorbance of treated cultures/absorbance of control cultures] $\times 100$.

Apoptosis and cell cycle assays. In $100 \mu 1$ medium, $2 \times 10^{4}$ cells/well (cell lines) or $10^{5}$ cells/well (patient samples) were cultured in 96well plates for $24 \mathrm{~h}$ in the presence or absence of AZA, CUR and AZA plus CUR. Apoptosis was evaluated by measuring annexin-VFITC and propidium iodide (PI) binding, using Annexin-V apoptosis detection kit (Santa Cruz Biotechnology, Dallas, TX, USA). Viable cells were negative for both annexin-V-FITC and PI, early apoptotic cells were positive for annexin-V-FITC staining, and late apoptotic cells were positive for both annexin-V-FITC and PI staining. Cell cycle analysis was performed using DNA-Prep kit (Beckman Coulter, Nyon, Switzerland) for cell permeabilization and PI staining following the manufacturer's instructions. The samples were analyzed by flow cytometry using a FACSCanto II flow cytometer (Becton-Dickinson, East Rutherford, NJ, USA). Samples were run in duplicate with 10000 events counted per sample.

Cell differentiation assay. In $100 \mu 1$ medium, $2 \times 10^{4}$ cells/well (cell lines) or $10^{5}$ cells/well (patient samples) were cultured in 96-well plates for $24 \mathrm{~h}$ in the presence or absence of AZA, CUR and AZA plus CUR. Immunophenotyping was performed by staining cells with a panel of five specific monoclonal antibodies (CD34, CD11b, CD45, CD13, and HLA-DR). The samples were analyzed by flow cytometry using a FACSCanto II flow cytometer (BectonDickinson, East Rutherford, NJ, USA). Data were analyzed with Infinity software (Cytognos, Salamanca, Spain). Samples were run in duplicate with 30000 events counted per sample.

Statistical analysis. Statistical differences were determined using two-tailed Student's $t$-test for dual comparisons. Data are expressed as mean \pm standard deviation (SD). Significance was accepted at $* p<0.05$ and $* * p<0.01$ levels.

\section{Results}

Combination of AZA and CUR synergistically inhibited proliferation in leukemia cell lines. To determine the effect of AZA and CUR on cell viability, AML-derived cell lines were treated in vitro for 24 or $48 \mathrm{~h}$ with increasing doses of the two drugs. Results showed that AZA treatment inhibited growth of HL-60, U-937, and K-562 cell lines in a time- and dosedependent manner, showing an approximate inhibition rate after $24 \mathrm{~h}$ of $15 \%$ at dose of $1 \mu \mathrm{M}$ and $25 \%$ at dose of $2 \mu \mathrm{M}$ (Figure 1A). In contrast, AZA did not inhibit growth of OCIAML3 at any dose examined (Figure 1A). On the other hand, CUR inhibited cell proliferation in all cell lines tested in a time- and dose-dependent manner, reaching an optimal of $25 \%$ inhibition rate at $10 \mu \mathrm{M}$ in HL-60, K-562, and OCI-AML3 cells and $40 \%$ at $5 \mu \mathrm{M}$ in U-937 cells (Figure 1A). For the combination assays, two concentrations of AZA (1 and $2 \mu \mathrm{M})$ and CUR (5 and $10 \mu \mathrm{M}$ ) were examined. The highest synergistic effect was observed at $1 \mu \mathrm{M}$ AZA/10 $\mu \mathrm{M}$ CUR in HL-60, K-562, and OCI-AML3 cells and at $1 \mu \mathrm{M}$ AZA/5 $\mu \mathrm{M}$ CUR in U-937 cells (Figure 1B). For both U-937 and K-562 

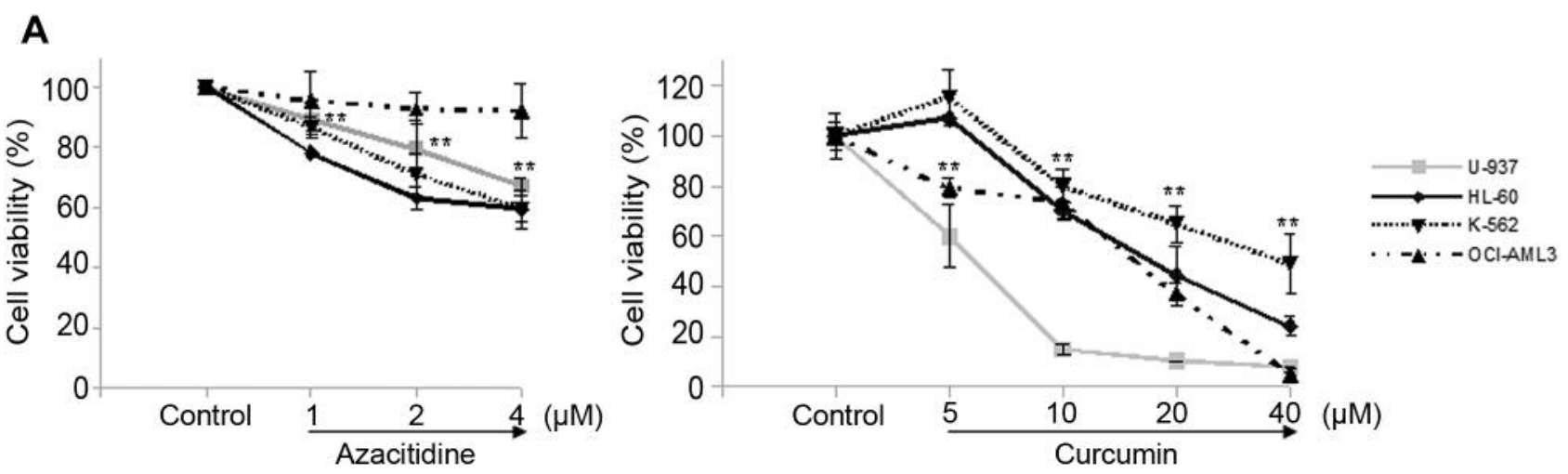

B
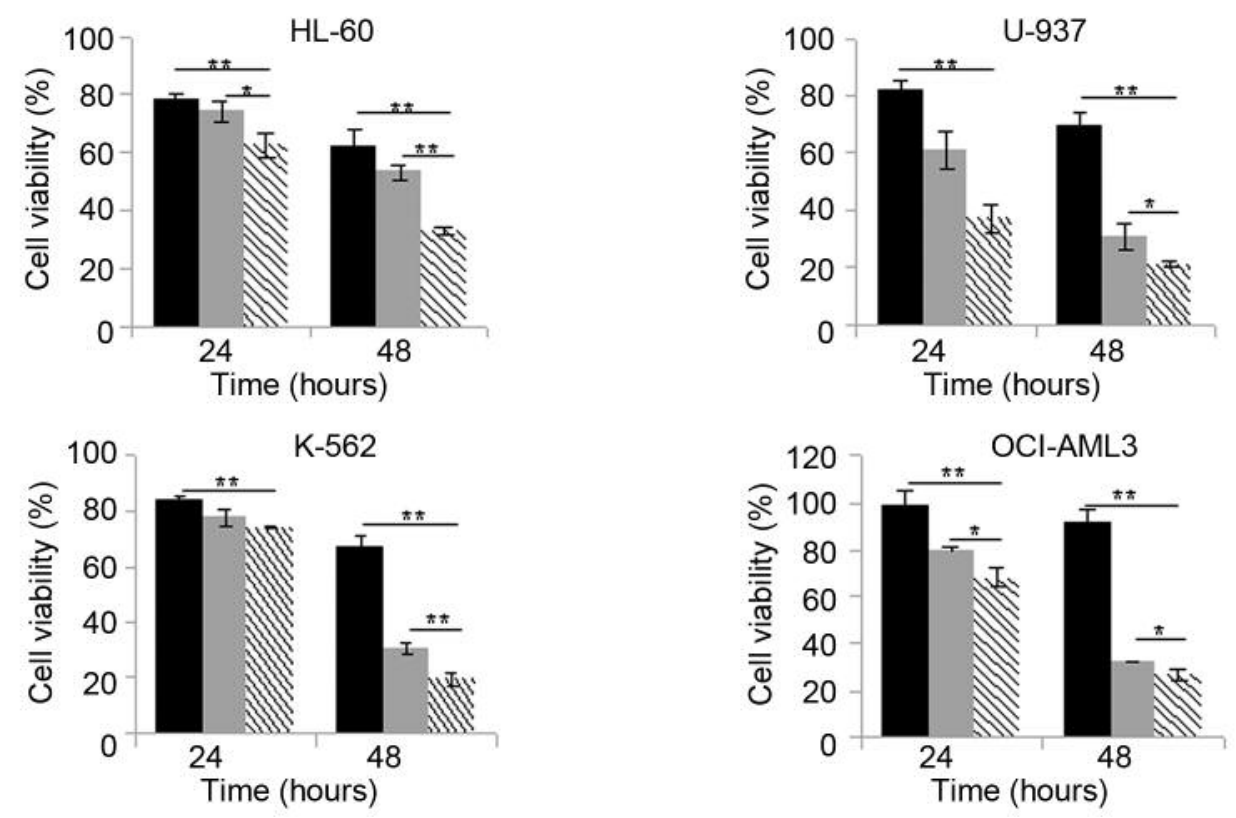

- AZA

: Curcumin

$\therefore A Z A+$ Curcumin

Figure 1. AZA and CUR inhibit growth of myeloid leukemia cell lines. (A) HL-60, U-937, K-562, and OCI-AML3 cells were exposed to different concentrations of AZA (left) and CUR (right) for 24 h. Significant growth inhibition was observed in all the leukemic lines following treatment with AZA at concentrations higher than $1 \mu M$, except in the OCI-AML3 line where no significant growth inhibition was observed at the three doses tested. Significant growth inhibition was also observed in HL-60 and K-562 cells treated with CUR at concentrations higher than $10 \mu M$ and in U-937 cells and OCI-AML3 cells treated with CUR at concentrations higher than $5 \mu M$. (B) All leukemic lines were exposed for 24 or $48 \mathrm{~h}$ to AZA, CUR and a combination of the two drugs. The AZA/CUR combination synergistically inhibited proliferation following treatment for $24 \mathrm{~h}$ or $48 \mathrm{~h}$ in all leukemic lines. Cell growth, expressed as the percentage of cell viability relative to the control cultures (100\%) for each cell line, was assessed in duplicate samples. Results are expressed as mean $\pm S D$ of pooled data from two experiments. ${ }^{*} p<0.05$ and ${ }^{*} p<0.01$ with respect to control untreated cells.

cell lines incubation for $48 \mathrm{~h}$ was necessary to observe a significant synergistic inhibitory effect. These combinations were selected for the next functional assays.

Combination of AZA and CUR synergistically induced apoptosis and may also alter cell cycle in leukemia cell lines. Next, we hypothesized that induction of apoptosis might account for the reduced cell proliferation in treated cultures. CUR significantly increased early and late apoptosis in all leukemic cell lines (Figure 2A and B). AZA increased significantly apoptosis only in U-937 cells (early apoptosis, $7.1 \%$ vs. $10.1 \%$, for untreated and AZA treated cells respectively; $p<0.01)$. Interestingly, a significant synergistic effect was observed with the AZA/CUR combination in all cell lines either in early apoptosis (K-562; Figure 2B) or in late apoptosis (HL60, U-937, and OCI-AML3; Figure 2B).

To assess if the growth inhibitory effect of the two drugs might also involve cell cycle arrest, cell proportions in different phases of the cell cycle were measured by flow cytometry assay. AZA caused cell cycle alteration in two of the four cell 
A OCI-AML3:
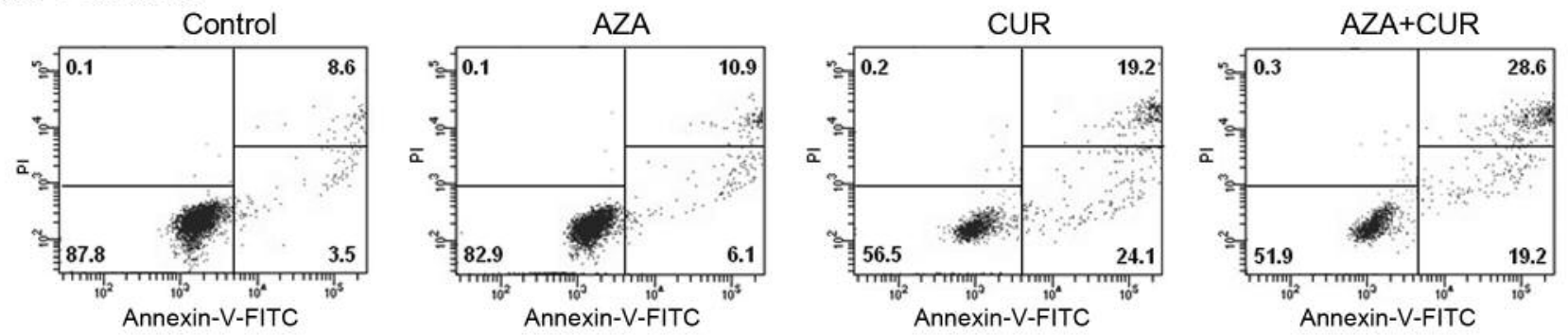

B All leukemic lines:
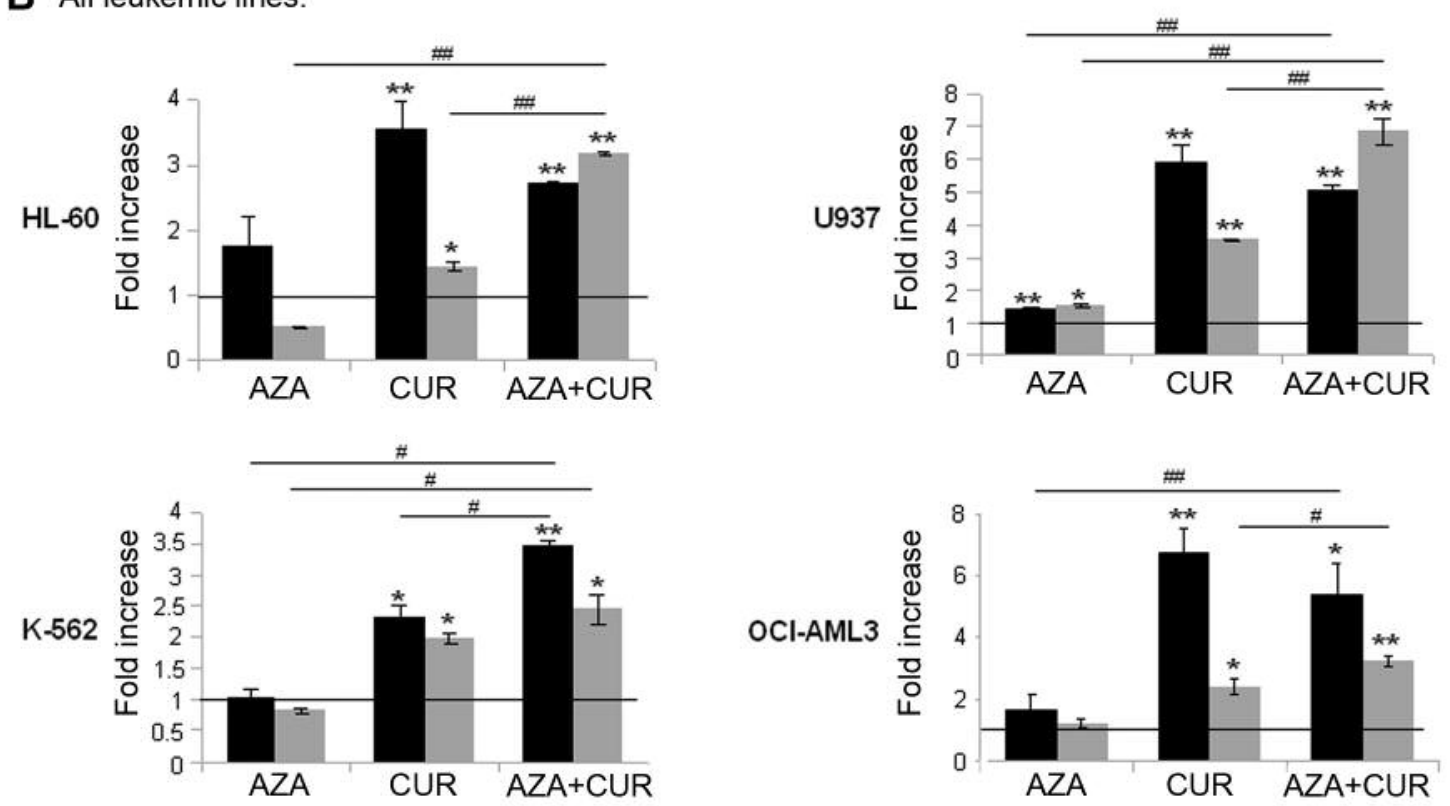

- Early apoptosis $=$ Late apoptosis

Figure 2. AZA, CUR and their combination induce apoptosis in leukemic cell lines. (A) OCI-AML3 cells treated without (control culture) or with drugs ( $1 \mu M$ AZA, $10 \mu M$ CUR and $1 \mu M$ AZA/10 $\mu M$ CUR, for $24 \mathrm{~h}$ ) were stained with PI and Annexin-V-FITC and analyzed by flow cytometry. The indicated percentages refer to total analyzed cells. Results shown are from one representative of two independent assays. (B) Fold increase (relative to control untreated cultures of each cell line) of early and late apoptosis in leukemic cell lines treated and analyzed as indicated in (A) for OCI-AML3 cells. Values higher than 1 (horizontal bar) indicate increased apoptosis in AZA, CUR or AZA/CUR treated cells. Data are presented as mean $\pm S D$ from two experiments. ${ }^{*} p<0.05$, and ${ }^{* *} p<0.01$ with respect to control untreated cells. ${ }^{*} p<0.05$, and ${ }^{\# \#} p<0.01$ with respect to different treatment groups.

lines tested, while CUR caused cell cycle alteration in three of the four cell lines (Figure 3A). Treatment of U-937 and K-562 cells with AZA for $24 \mathrm{~h}$ increased significantly the percentage of cells in the $\mathrm{G}_{0} / \mathrm{G}_{1}$ phase. In contrast, CUR treatment caused more heterogeneous cell cycle arrest in the different cell lines; significantly increased percentage of cells in the $\mathrm{G}_{0} / \mathrm{G}_{1}$ phase in U-937 cells and in the M phase in K-562 and OCI-AML3 cells (Figure 3B). No relevant changes were detected in the HL-60 cells, and the significant decrease in the G0/G1 phase observed following CUR treatment $(51.5 \%$ vs. $34.8 \%$, for untreated and CUR treated respectively; $p<0.05$ ) could be explained by a decrease in viable cells due to a high rate of apoptosis. Finally, a synergistic effect on cell cycle was not detected with the AZA/CUR combination.
Combination of AZA and CUR synergistically inhibited proliferation and induced apoptosis in bone marrow samples of patients. We evaluated the effect of AZA and CUR on two healthy bone marrow samples and six primary bone marrow samples of AML and MDS (Table I). In healthy bone marrow samples, AZA, CUR or their combination did not induce a significant growth inhibition (Figure 4A) or a significant increase in early or late apoptosis (Figure 4B).

In contrast, samples (Table I), we observed a notable effect of CUR on growth inhibition in the six bone marrow patient samples as well as a synergistic effect of the AZA/CUR combination in five of the six studied samples (S1, S3, S4, S5 and S6; Figure 5A). The synergistic effect of 
A
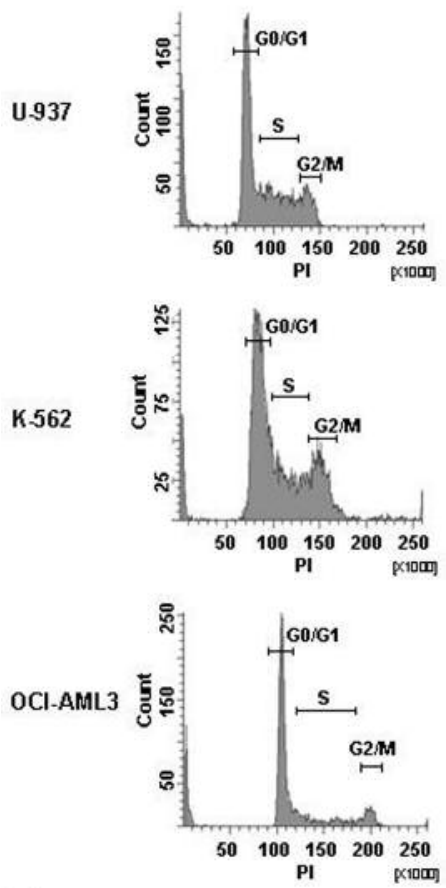

B

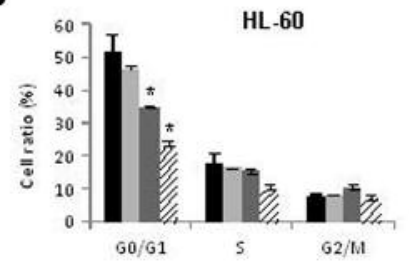

AZA
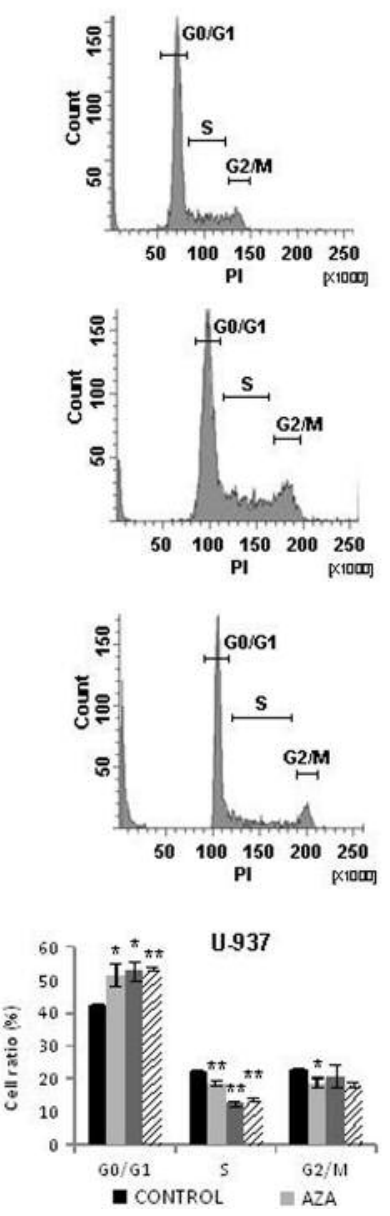

CUR
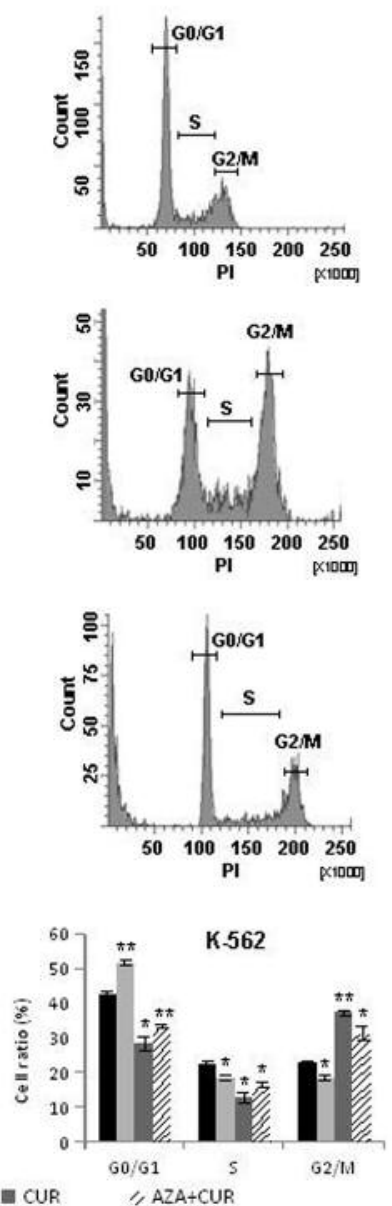

AZA+CUR
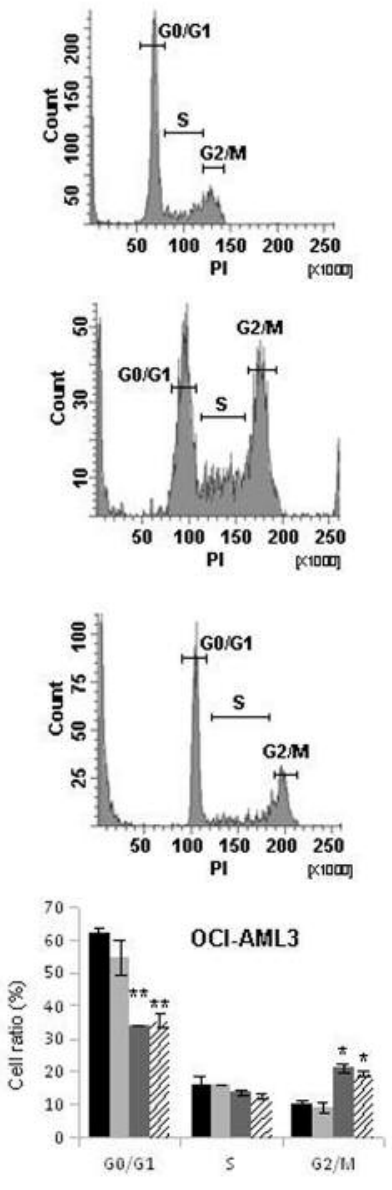

Figure 3. AZA or CUR leads to cell-cycle arrest in some leukemic cell lines. (A) U-937, K-562 and OCI-AML3 cells treated without (control culture) or with drugs (AZA, CUR, and AZA/CUR for $24 \mathrm{~h}$ ) were permeabilized, stained with PI, and DNA contents were analyzed by flow cytometry. Gates of cells in different cell cycle phases are indicated. (B) The indicated cell lines, with or without treatments were permeabilized and stained with PI, and DNA contents were analyzed by flow cytometry. The percentage of cells in each phase of the cell cycle is shown. Data are presented as mean \pm SD from two experiments. $* p<0.05$, and $* * p<0.01$ with respect to control untreated cells.

the two drugs on proliferation can be clearly observed in sample S6, in which AZA barely inhibited growth and CUR inhibited it moderately, while combining them produced a very high degree of inhibition (proliferation S6, 98\% AZA vs. $79.3 \%$ CUR vs. $42.4 \%$ AZA/CUR, $p<0.01$; Figure 5A). Regarding apoptosis, AZA had a small effect on patient samples, whereas CUR induced a significant increase in early and late apoptosis in all samples except for S5 (Figure 5B). Finally, AZA/CUR combination assays showed a synergistic effect on apoptosis in four of the six studied samples (S2, S3, S5 and S6; Figure 5B).

The combination of AZA and CUR did not induce differentiation in myeloid leukemia cell lines and patient samples. To study the effect of AZA and CUR on differentiation, we performed the immunophenotyping of leukemia cell lines and bone marrow patient samples incubated for $24 \mathrm{~h}$ in the presence or absence of each drug and their combination, by staining cells with 5 monoclonal antibodies (CD34, CD11b, CD45, CD13, and HLA-DR). Under these conditions, no significant immunophenotypic differences were found in the four leukemic cells lines treated with AZA, CUR or AZA/CUR. On the other hand, in two patient samples with a high percentage of blasts (S3, $50 \%$; S6, 76\%) and high cell mortality after adding the combination of drugs, it was not possible to study differentiation, while in the four remaining samples (S1, S2, S4 and S5) no significant differences were observed. 

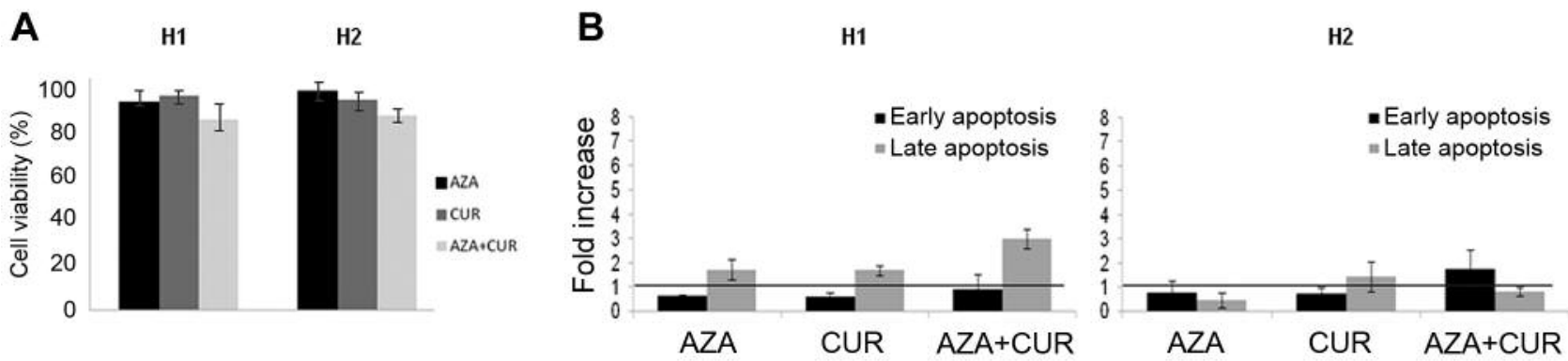

Figure 4. Effects of AZA and CUR on healthy bone marrow cells. (A) AZA, CUR and AZA/CUR combination did not significantly inhibit growth on two samples (H1 and H2) from healthy volunteers. Cell growth was expressed as the percentage of cell viability in relation to control cultures (100\%). Results are expressed as mean $\pm S D$ of pooled data from two experiments. (B) AZA, CUR and AZA/CUR combination did not significantly increase early or late apoptosis in the two samples of healthy bone marrow. In the H1 sample, a modest increase in late apoptosis can be observed with the AZA/CUR combination, although it was not significant $(p=0.09)$. Values higher than 1 (horizontal bar) indicate increased apoptosis in $A Z A, C U R$ or AZA/CUR treated cells. Data are expressed as mean $\pm S D$ from two experiments.

Table I. Main characteristics of patient samples.

\begin{tabular}{lcccccc}
\hline Patient & Pathology & Age (years) & Gender & Karyotype & Genes mutated* & Survival (months), status \\
\hline S1 & MDS & 83 & Male & 46, XY & TET2 & $2.4(\mathrm{a})$ \\
S2 & AML & 65 & Male & 46, XY & ASXL1 & $3.6(\mathrm{a})$ \\
S3 & AML & 65 & Male & 46, XY & ASXL1, SRSF, TET2 & $4.2(\mathrm{a})$ \\
S4 & AML & 75 & Female & 45, XX, & ASXL1, TET2 & $3.4(\mathrm{~d})$ \\
S5 & MDS & 82 & Male & $46, X Y$ & SF3B1, TET2 & $1.1(\mathrm{a})$ \\
S6 & AML & 69 & Male & $46, X Y$ & FLT3, IDH2 & $1.3(\mathrm{a})$ \\
\hline
\end{tabular}

MDS: Myelodysplastic syndrome; AML: acute myeloid leukemia; status, d: dead; a: alive. *A diagnostic panel with the most frequently mutated genes in myeloid diseases was studied: FLT3, CEBPA, NPM1, NRAS, KRAS, ASXL1, TET2, DNMT3A, IDH1, IDH2, EZH2, TP53, SRSF2, SF3B1, $U 2 A F 1, S E T B P 1$ and $J A K 2$.

\section{Discussion}

The hypomethylating drug AZA is an effective pharmacological option for MDS and older AML patients; however, only half of patients show response to treatment (57). Curcumin and curcuminoids, natural compounds of the rhizome of the plant Curcuma longa, have demonstrated antileukemic activity individually, but also in combination with other agents such as hypomethylating drugs (20). Furthermore, the selective ability of curcumin to attack tumor cells and not healthy cells makes it an attractive candidate for drug development $(25,26)$. In the present in vitro study, we investigated the effect of the combination of AZA and CUR on leukemia cell lines and bone marrow patient samples and report for the first time their synergistic antioncogenic activity in hematologic myeloid neoplasms.

First, we studied the effect of AZA and CUR on cell proliferation in four myeloid leukemia cell lines: U-937, HL60, K-562, and OCI-AML3. As shown in previous studies, AZA induced a time- and concentration-dependent inhibitory effect on U-937, HL-60, and K-562 cells $(2,27)$, and a small inhibitory effect on OCI-AML3 cells (28). The OCI-AML3 cells carry a NPM1 gene mutation (type A) and a mutation in the DNA methyltransferase gene DNMT3A (R882C). It has been reported that DNMT3A mutation in OCI-AML3 cells results in a decrease in the average level of DNA methylation and less methylated $\mathrm{CpG}$ dinucleotides than wild-type DNMT3A cells (29). Accordingly, as a hypomethylating drug, AZA showed a very low growth inhibition of OCI-AML3 cells. However, establishing the possible lack of efficiency of hypomethylating drugs in DNMT3A-mutated cells with globally hypomethylated genomes requires a greater number of functional and molecular studies. As regards the effect of CUR on growth inhibition, the leukemic cell lines showed different sensitivity. In HL-60, K-562, and OCI-AML3 cells, CUR showed a high inhibition rate at a dose of $10 \mu \mathrm{M}$, whereas in U-937 cells the single dose of $5 \mu \mathrm{M}$ CUR was sufficient to cause a very high rate of growth inhibition. Curcuminrelated cell death in HL-60 and K-562 has been associated 


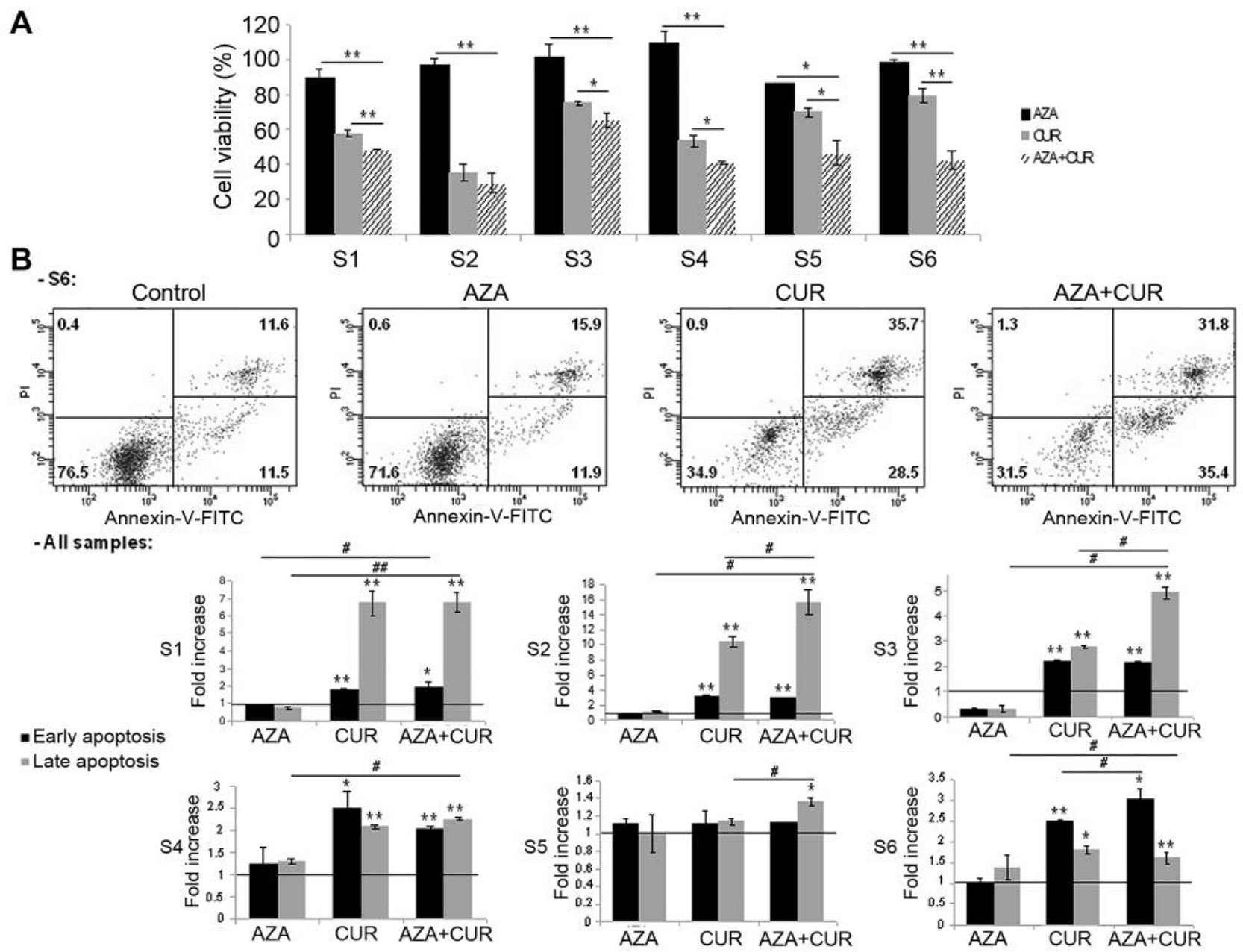

Figure 5. AZA and CUR inhibit growth and apoptosis in patient samples. (A) Six patient samples were exposed for $24 h$ to AZA, CUR and a combination of the two drugs. The AZA/CUR combination significantly inhibited proliferation in all samples. Cell growth was expressed as the percentage of cell viability in relation to the control cultures (100\%). Results are expressed as mean $\pm S D$ of pooled data from two experiments. (B) At the top, the cells of S6 patient treated without (control culture) or with the drugs (1 $\mu M$ AZA, $10 \mu M$ CUR and $1 \mu M$ AZA/10 $\mu M$ CUR, for 24 h) were stained with PI and Annexin-V-FITC and apoptosis was analyzed by flow cytometry. The indicated percentage refers to total analyzed cells. On the bottom, fold increase (relative to control untreated cultures of each patient sample) of early and late apoptosis of patient cells treated and analyzed as the S6 sample. Values higher than 1 (horizontal bar) indicate increased apoptosis in AZA, CUR or AZA/CUR treated cells. Data are expressed as mean $\pm S D$ from two experiments. ${ }^{*} p<0.05$, and ${ }^{* *} p<0.01$ with respect to control untreated cells. ${ }^{\#} p<0.05$, and ${ }^{\# \#} p<0.01$ with respect to different treatment groups.

with the activation of caspases- 9 and -3 (30), whereas the high sensitivity of U-937 to CUR has been directly associated with the expression of interferon-regulating genes that increased apoptosis (17). Finally, as in solid tumors (21), the AZA/CUR combination offers significant advantages in growth inhibition compared to the use of either drug alone.

This combination seems to inhibit growth via apoptosis induction and, at least in some cases, by altering the cell cycle. In the study of apoptosis, we observed a small effect in cells treated with AZA, whereas CUR treatment increased apoptosis levels to a far greater degree. The effect of AZA on apoptosis lies in its DNA hypomethylation effect that allows the re-expression of tumor-suppressor genes, triggering leukemic cell death $(1,2,27,28)$. In contrast to AZA, which traps endogenous methyltransferase DNMT1, CUR also functions as a hypomethylating agent but by disrupting DNMT1 synthesis and chemically inhibiting its enzymatic activity (31). In addition, it has been reported that CUR may also act to inhibit histone deacetylases (32). Because the two drugs operate using different mechanisms, we speculated that together they could have additive or synergistic antileukemic activity. This hypothesis on the 
synergistic behaviour between AZA and CUR was first demonstrated in leukemic lines. The combination of these drugs increased the different stages of apoptosis to a greater degree than each drug separately.

Regarding cell cycle, our results showed that when K-562 cells were treated with AZA, cell cycle was arrested in the $\mathrm{G}_{0} / \mathrm{G}_{1}$ phase, while in a previous report it was shown that AZA induced arrest in the $G_{2}$ phase (27). This difference may be explained by the different dose of AZA $(4 \mu \mathrm{M})$ and incubation time (48 h) used in that study compared to ours. CUR induced arrest in the $G_{0} / G_{1}$ phase of the cell cycle in U-937 cells and in the $M$ phase in K-562 cells, coinciding with published results $(16,33)$. In contrast, no significant arrest in the G1 phase was detected in HL-60 cells (30), perhaps due to the high level of apoptosis. Finally, M phase cell arrest in OCI-AML3 cells by CUR is very interesting because its efficacy in this cell line, which has a very frequent mutational profile in AML (34), has not been previously analyzed.

AZA, CUR or their combination did not induce differentiation in any of the assays performed. Admittedly, previous reports have shown that AZA and CUR induced differentiation of HL-60 cells only when combined with vitamin D $(35,36)$. However, we considered that, given the morphological variability between the lines, this assay should be performed in other leukemic lines as well as in human samples in order to confirm the absence of differentiation. Based on these initial and other more recent reports (23), future studies adding vitamin $\mathrm{D}$ to the AZA/CUR combination would be useful.

Both drugs were tested in healthy samples and no significant effects were found, which also shows that CUR, as in previous reports, has a low cytotoxic effect in nontumor cells $(25,26,33)$. In contrast, in bone marrow samples of myeloid neoplasms, CUR had a high antileukemic activity and, interestingly, the AZA/CUR combination showed in most of them, synergistic antioncogenic effects by increasing apoptosis. This synergistic activity can be clearly observed in sample S6, which along with other alterations carries a FLT3 mutation; the sensitivity of this mutational profile to the CUR action has been demonstrated in vitro (37).

Therefore, our data together with the findings of others (15-17, 30, 33, 38), support the usefulness of CUR in the treatment of malignant hematological tumors. However, it seems that CUR cannot completely suppress tumor growth and should be administered in combination with other clinically effective agents (31). Consequently, we suggest AZA as an effective complementary agent. Elderly AML and MDS patients are not suitable transplantation candidates and have limited therapeutic options outside of conventional chemotherapy and hypomethylating agents $(39,40)$. The inclusion of these patients in clinical trials is currently recommended, and the data obtained from trials in which
CUR is used alone or in combination to treat hematological neoplasms $(9,23)$, together with our results, invite development of a future clinical trial based on the AZA/CUR combination. Although more functional studies are needed to explore this combination, as well as the molecular mechanisms behind its activity, we suggest that it has the potential to be used as a future therapeutic alternative in AML and MDS.

We provide, for the first-time, evidence on the in vitro efficacy of the AZA/CUR combination treatment. This combination of drugs showed synergistic activity in growth inhibition and apoptosis induction both in leukemic cell lines and in patient samples of AML and MDS. In addition, the AZA/CUR combination showed low cytotoxicity for healthy cells, which increases its potential as a future therapeutic option. Further studies of this combination in vivo using animal models of leukemia to analyze the pharmacokinetics and pharmacodynamics are justified, and would be a preliminary step in the design of a clinical trial to evaluate its real clinical benefit.

\section{Conflicts of Interest}

The Authors declare that they have no conflict of interest regarding this study.

\section{Authors' Contributions}

IM and EV conceived, designed and performed the experiments. FG maintained the cell lines. PA and MJR analyzed the cytometry data. MC and JCHB provided clinical data. MT and CS coordinated all activities and discussions. IM, EV and BN wrote the manuscript. All Authors discussed the results and commented on the manuscript.

\section{Acknowledgements}

The Authors would like to thank Belén Jiménez, Paula Coll and Fernando Domingo, for their excellent assistance in cell culture and cytometry assays.

Funding: This work was supported by the grant INT 00038 from INCLIVA (Spain).

\section{References}

1 Itzykson R and Fenaux P: Epigenetics of myelodysplastic syndromes. Leukemia 28: 497-506, 2014. PMID: 24247656. DOI: 10.1038/leu.2013.343

2 Su Y, Xu H, Xu Y, Yu J, Xian Y and Luo Q: Azacytidine inhibits the proliferation of human promyelocytic leukemia cells (HL60) by demethylation of MGMT, DAPK and p16 genes. Hematology 17: 41-46, 2012. PMID: 22549447. DOI: $10.1179 / 102453312$ X13221316477624

3 Gambari R, del Senno L, Barbieri R, Viola L, Tripodi M, Raschellà $\mathrm{G}$ and Fantoni A: Human leukemia K-562 cells: induction of erythroid differentiation by 5-azacytidine. Cell Differ 14: 87-97, 1984. PMID: 6205767. 
4 Nguyen AN, Luna-Moran A, Richard N, Belka I, Brady H and MacBeth K: Azacitidine induces differentiation of acute myeloid leukemia cell lines along the granulocytic/monocytic lineage. In: 101st Annual Meeting of the American Association for Cancer Research. Cancer Res 70(8), 2010. DOI: 10.1158/1538-7445.AM 10-191

5 Fenaux P, Mufti GJ, Hellstrom-Lindberg E, Santini V, Finelli C, Giagounidis A, Schoch R, Gattermann N, Sanz G, List A, Gore SD, Seymour JF, Bennett JM, Byrd J, Backstrom J, Zimmerman L, McKenzie D, Beach $\mathrm{C}$ and Silverman LR: Efficacy of azacitidine compared with that of conventional care regimens in the treatment of higher-risk myelodysplastic syndromes: a randomised, open-label, phase III study. Lancet Oncol 10: 223-232, 2009. PMID: 19230772. DOI: 10.1016/S1470-2045(09)70003-8

6 Dombret H, Seymour JF, Butrym A, Wierzbowska A, Selleslag D, Jang JH, Kumar R, Cavenagh J, Schuh AC, Candoni A, Récher C, Sandhu I, Bernal del Castillo T, Al-Ali HK, Martinelli G, Falantes J, Noppeney R, Stone RM, Minden MD, McIntyre $\mathrm{H}$, Songer S, Lucy LM, Beach CL and Döhner H: International phase 3 study of azacitidine vs conventional care regimens in older patients with newly diagnosed AML with $>30 \%$ blasts Blood 126: 291-299, 2015. PMID: 25987659. DOI: 10.1182/ blood-2015-01-621664

7 Shapiro RM and Lazo-Langner A: Systematic review of azacitidine regimens in myelodysplastic syndrome and acute myeloid leukemia. BMC Hematol 18: 3, 2018. PMID: 294353 31. DOI: $10.1186 / \mathrm{s} 12878-017-0094-8$

8 Unnikrishnan A, Papaemmanuil E, Beck D Deshpande NP, Verma A, Kumari A, Woll PS, Richards LA, Knezevic K, Chandrakanthan V, Thoms JAI, Tursky ML, Huang Y, Ali Z, Olivier J, Galbraith S, Kulasekararaj AG, Tobiasson M, Karimi M, Pellagatti A, Wilson SR, Lindeman R, Young B, Ramakrishna R, Arthur C, Stark R, Crispin P, Curnow J, Warburton P, Roncolato F, Boultwood J, Lynch K, Jacobsen SEW, Mufti GJ, Hellstrom-Lindberg E, Wilkins MR, MacKenzie KL, Wong JWH, Campbell PJ and Pimanda JE: Integrative genomics identifies the molecular basis of resistance to azacitidine therapy in myelodysplastic syndromes. Cell Rep 20: 572585, 2017. PMID: 28723562. DOI: 10.1016/j.celrep.2017.06.067

9 Nebbioso A, Carafa V, Benedetti R and Altucci L: Trials with 'epigenetic' drugs: an update. Mol Oncol 6: 657-682, 2012. PMID: 23103179. DOI: 10.1016/j.molonc.2012.09.004

10 DiNardo CD, Pratz K, Pullarkat V, Jonas BA, Arellano M, Becker PS, Frankfurt O, Konopleva M, Wei AH, Kantarjian HM Xu T, Hong WJ, Chyla B, Potluri J, Pollyea DA and Letai A: Venetoclax combined with decitabine or azacitidine intreatmentnaive, elderly patients with acute myeloid leukemia. Blood 133 7-17, 2019. PMID: 30361262. DOI: 10.1182/blood-2018-08868752

11 Guan F, Ding Y, Zhang Y, Zhou Y, Li M and Wang C: Curcumin suppresses proliferation and migration of MDA-MB-231 breast cancer cells through autophagy-dependent Akt degradation. PLoS One 11: e0146553, 2016. PMID: 26752181. DOI: 10.1371/journal.pone.0146553

12 Li Y, Domina A, Lim G, Chang T and Zhang T: Evaluation of curcumin, a natural product in turmeric, on Burkitt lymphoma and acute myeloid leukemia cancer stem cell markers. Future Oncol 14: 2353-2360, 2018. PMID: 30139269. DOI: 10.2217/ fon-2018-0202

13 Zeng Y, Weng G, Fan J, Li Z, Wu J, Li Y, Zheng R, Xia P and Guo K: Curcumin reduces the expression of survivin, leading to enhancement of arsenic trioxide-induced apoptosis in myelodysplastic syndrome and leukemia stem-like cells. Oncol Rep 36: 1233-1242, 2016. PMID: 27430728. DOI: 10.3892/ or.2016.4944

14 Larasati YA, Yoneda-Kato N, Nakamae I, Yokoyama T, Meiyanto E and Kato JY: Curcumin targets multiple enzymes involved in the ROS metabolic pathway to suppress tumor cell growth. Sci Rep 8: 2039, 2018. PMID: 29391517. DOI: 10.10 38/s41598-018-20179-6

15 Kouhpeikar H, Butler AE, Bamian F, Barreto GE, Majeed M and Sahebkar A: Curcumin as a therapeutic agent in leukemia. J Cell Physiol 234: 12404-12414, 2019. PMID: 30609023. DOI: $10.1002 /$ jcp. 28072

16 Martinez-Castillo M, Bonilla-Moreno R, Aleman-Lazarini L, Meraz-Rios MA, Orozco L, Cedillo-Barron L, Cordova EJ and Villegas-Sepulveda N: A subpopulation of the K562 cells are killed by curcumin treatment after $\mathrm{G}_{2} / \mathrm{M}$ arrest and mitotic catastrophe. PLoS One 11: e0165971, 2016. PMID: 27832139. DOI: 10.1371 journal.pone.0165971

17 Zhang Y, Kong Y, Liu S, Zeng L, Wan L and Zhang Z: Curcumin induces apoptosis in human leukemic cell lines through an IFIT2-dependent pathway. Cancer Biol Ther 18: 43-50, 2017. PMID: 28071969. DOI: 10.1080/15384047.2016.1276129

18 Zhuang W, Long L, Zheng B, Ji W, Yang N, Zhang Q and Liang Z: Curcumin promotes differentiation of glioma-initiating cells by inducing autophagy. Cancer Sci 103: 684-690, 2012. PMID: 22192169. DOI: 10.1111/j.1349-7006.2011.02198.x

19 Kini AR, Nagabhushan M, Tallman MS and Roychowdhury S: Curcumin enhances differentiation of all-trans retinoic acid (ATRA)-sensitive and ATRA-resistant acute promyelocytic (APL) cells. In: 47th Annual Meeting of American Society of Hematology. Blood 106: 4456, 2005.

20. Hassan HE, Keita JA, Narayan L, Brady SM, Frederick R, Carlson S, C Glass K, Natesan S, Buttolph $T$ and Fandy TE: The combination of dimethoxycurcumin with DNA methylation inhibitor enhances gene re-expression of promoter-methylated genes and antagonizes their cytotoxic effect. Epigenetics 11: 740-749, 2016. PMID: 27588609. DOI: 10.1080/15592294.2016.1226452

21 Dubey V and Owusu-Apenten R: Curcumin restores glutathiones-transferase activity for LNCaP prostate cancer cells. Pure App Chem Sci 2: 61-72, 2014. DOI: 10.12988/pacs.2014.411

22 Carroll RE, Benya RV, Turgeon DK, Vareed S, Neuman M, Rodriguez L, Kakarala M, Carpenter PM, McLaren C, Meyskens FL Jr. and Brenner DE: Phase IIa clinical trial of curcumin for the prevention of colorectal neoplasia. Cancer Prev Res (Phila) 4: 354-364, 2011. PMID: 21372035. DOI: 10.1158/1940-6207. CAPR-10-0098

23 William B, James A and Solove R: A Phase II Study of Curcumin and Vitamin D in previously untreated patients with early stage chronic lymphocytic leukemia or small lymphocytic lymphoma. In: 60th Annual Meeting of American Society of Hematology. Blood 132: 1875, 2018. DOI: 10.1182/blood-2018-99-112295

24 Datta S, Misra SK, Saha ML, Lahiri N, Louie J, Pan D and Stang PJ: Orthogonal self-assembly of an organoplatinum(II) metallacycle and cucurbit[8]uril that delivers curcumin to cancer cells. Proc Natl Acad Sci USA 115: 8087-8092, 2018. PMID: 30038010. DOI: $10.1073 /$ pnas.1803800115

25 Ravindran J, Prasad S and Aggarwal BB: Curcumin and cancer cells: how many ways can curry kill tumor cells selectively? AAPS J 11: 495-510, 2009. PMID: 19590964. DOI: 10.1208/s12 248-009-9128-x 
26 Sordillo PP and Helson L: Curcumin and cancer stem cells: curcumin has asymmetrical effects on cancer and normal stem cells. Anticancer Res 35: 599-614, 2015. PMID: 25667437.

27 Deng G, Li ZQ, Zhao C, Yuan Y, Niu CC, Zhao C, Pan J and Si WK: WNT5A expression is regulated by the status of its promoter methylation in leukaemia and can inhibit leukemic cell malignant proliferation. Oncol Rep 25: 367-376, 2011. PMID: 21165581. DOI: $10.3892 /$ or.2010.1108

28 Lund K, Cole JJ, VanderKraats ND, McBryan T, Pchelintsev NA, Clark W, Copland M, Edwards JR and Adams PD: DNMT inhibitors reverse a specific signature of aberrant promoter DNA methylation and associated gene silencing in AML. Genome Biol 15: 406, 2014. PMID: 25315154. DOI: 10.1186/s13059014-0406-2

29 Ferreira HJ, Heyn H, Vizoso M, Moutinho C, Vidal E, Gomez A, Martínez-Cardús A, Simó-Riudalbas L, Moran S, Jost E and Esteller M: DNMT3A mutations mediate the epigenetic reactivation of the leukemogenic factor MEIS1 in acute myeloid leukemia. Oncogene 35: 3079-3082, 2016. PMID: 26434589. DOI: $10.1038 /$ onc. 2015.359

30. Martínez-Castillo M, Villegas-Sepúlveda N, Meraz-Rios MA, Hernández-Zavala A, Berumen J, Coleman MA, Orozco L and Cordova EJ: Curcumin differentially affects cell cycle and cell death in acute and chronic myeloid leukemia cells. Oncol Lett 15: 6777-6783, 2018. PMID: 29616136. DOI: 10.3892/ol.2018. 8112

31 Yu J, Peng Y, Wu LC, Xie Z, Deng Y, Hughes T, He S, Mo X, Chiu M, Wang QE, He X, Liu S, Grever MR, Chan KK and Liu $\mathrm{Z}$ : Curcumin down-regulates DNA methyltransferase 1 and plays an anti-leukemic role in acute myeloid leukemia. PLoS One 8: e55934, 2013. PMID: 23457487. DOI: 10.1371/journal.pone. 0055934

32 Chen CQ, Yu K, Yan QX, Xing CY, Chen Y, Yan Z, Shi YF, Zhao KW and Gao SM: Pure curcumin increases the expression of SOCS1 and SOCS3 in myeloproliferative neoplasms through suppressing class I histone deacetylases. Carcinogenesis 34: 1442-1449, 2013. PMID: 23430957. DOI: 10.1093/carcin/bgt070

33 Rao J, Xu DR, Zheng FM, Long ZJ, Huang SS, Wu X, Zhou WH, Huang RW and Liu Q: Curcumin reduces expression of Bcl-2, leading to apoptosis indaunorubicin-insensitive CD34+ acute myeloid leukemia cell lines and primary sorted CD34+ acute myeloid leukemia cells. J Transl Med 9: 71, 2011. PMID: 21595920. DOI: 10.1186/1479-5876-9-71
34 Alpermann T, Schnittger S, Eder C, Dicker F, Meggendorfer M, Kern W, Schmid C, Aul C, Staib P, Wendtner CM, Schmitz N, Haferlach C and Haferlach T: Molecular subtypes of NPM1 mutations have different clinical profiles, specific patterns of accompanying molecular mutations and varying outcomes in intermediate risk acute myeloid leukemia. Haematologica 101: e5558, 2016. PMID: 26471486. DOI: 10.3324/haematol. 2015.133819

35 Sokoloski JA, Shyam K and Sartorelli AC: Induction of the differentiation of HL-60 promyelocytic leukemia cells by curcumin in combination with low levels of vitamin D3. Oncol Res 9: 31-39, 1997. PMID: 9112258.

36 Doré BT, Chomienne C and Momparler RL: Effect of 5-aza-2'deoxycytidine and vitamin D3 analogs on growth and differentiation of human myeloid leukemic cells. Cancer Chemother Pharmacol 41: 275-280, 1998. PMID: 9488596. DOI: $10.1007 / \mathrm{s} 002800050740$

37 Tima S, Okonogi S, Ampasavate C, Berkland $\mathrm{C}$ and Anuchapreeda S: FLT3-specific curcumin micelles enhance activity of curcumin on FLT3-ITD overexpressing MV4-11 leukemic cells. Drug Dev Ind Pharm 45: 498-505, 2019. PMID: 30572745. DOI: 10.1080/03639045.2018.1562462

38 Bolger GT, Licollari A, Bagshaw R, Tan A, Greil R, Vcelar B, Majeed $\mathrm{M}$ and Sordillo P: Intense uptake of liposomal curcumin by multiple myeloma cell lines: comparison to normal lymphocytes, red blood cells and chronic lymphocytic leukemia cells. Anticancer Res 39: 1161-1168, 2019. PMID: 30842145. DOI: 10.21873 /anticanres.13225

39 Podoltsev NA, Stahl M, Zeidan AM and Gore SD: Selecting initial treatment of acute myeloid leukaemia in older adults. Blood Rev 31: 43-62, 2017. PMID: 27745715. DOI: 10.1016/ j.blre.2016.09.005

40 Aleshin A and Greenberg PL: Molecular pathophysiology of the myelodysplastic syndromes: insights for targeted therapy. Blood Adv 2: 2787-2797, 2018. PMID: 30352953. DOI: 10.1182/blood advances.2018015834 